Supporting Information

\title{
Synergetic bimetallic NiCo/CNTs catalyst for hydrogen production by glycerol steam reforming: effects of metal species distribution
}

Hui Zhou a, Shuangfei Liu a , Fangli Jing a, ${ }^{\text {* }}$, Shi-Zhong Luo ${ }^{\text {a }}$, Jun Shen a, Yanping Pang ${ }^{\text {b, }}$ Wei Chu ${ }^{\text {a }}$

a School of Chemical Engineering, Sichuan University, No. 24 South Section 1, Yihuan Road, 610065 Chengdu, China

${ }^{b}$ Sinopec Northwest Oilfield Branch, 830011 Urumqi, China 
$1 \quad N_{2}$ adsorption/desorption measurement
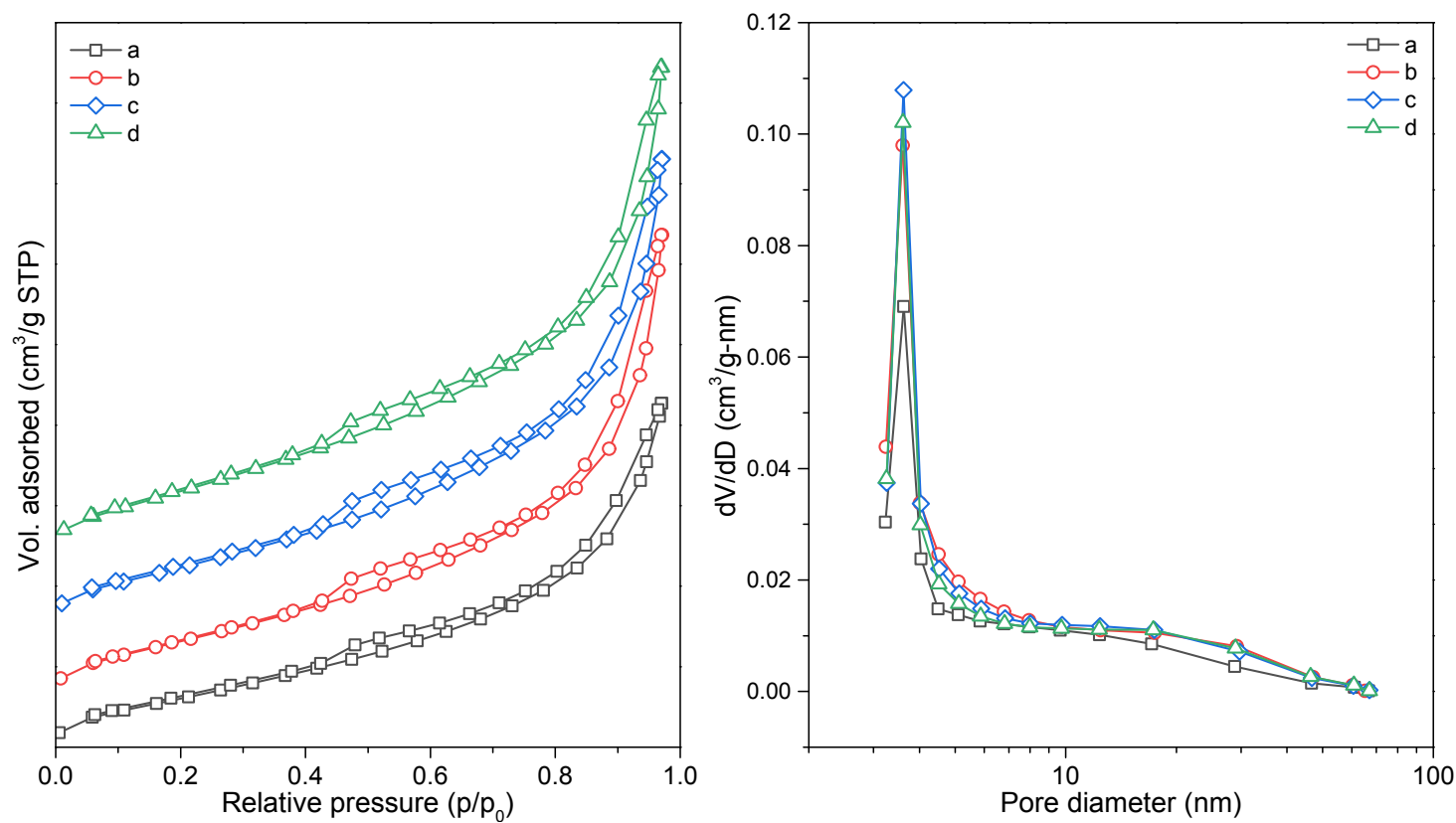

Figure S1 Isotherms (left) and pore size distributions (right) [a: Ni(i)Co(i)/CNTs, b: $\mathrm{Ni}(\mathrm{o}) \mathrm{Co}(\mathrm{o}) / \mathrm{CNTs}$, c: $\mathrm{Ni}(\mathrm{i}) \mathrm{Co}(\mathrm{o}) / \mathrm{CNTs}$ and d: $\mathrm{Ni}(\mathrm{o}) \mathrm{Co}(\mathrm{i}) / \mathrm{CNTs}]$ 


\section{Crystalline phases analysis by XRD}

The identification of crystalline phases was reported in Figure S2, nearly the same patterns were obtained whatever for the calcined or the reduced samples. The diffraction at $26.4^{\circ}$ and $42.6^{\circ}$ originated from the support CNTs. The Ni species existed as NiO (PDF\#471049 ) in calcined catalysts (Figure S21) due to the detected diffractions at $37.2^{\circ}, 43.3^{\circ}$ and $62.9^{\circ}, \mathrm{CoO}(\mathrm{PDF} \# 43-1004)$ was also detected though the corresponding diffractions at 36.5 o, $42.4^{\circ}$ and $61.5^{\circ}$ presented as weak shoulders.

The diffractions assigned to CNTs kept unchanged after reduction from Figure S2r (the diffraction peak at $26.4^{\circ}$ was not shown here), while the metal oxides including $\mathrm{NiO}$ and $\mathrm{CoO}$ were reduced to metallic $\mathrm{Ni}$ and $\mathrm{Co}$, respectively. The reduction could be easily observed as the diffractions ( $\mathrm{ca} .37^{\circ}$ and $\left.62^{\circ}\right)$ for the both metal oxides disappeared, and simultaneously the ones for metallic Ni (PDF\#04-0850, 44.5 ${ }^{\circ}, 51.9^{\circ}$ and $76.4^{\circ}$ ) and metallic Co (PDF\#15-0806, $44.3^{\circ}, 51.6^{\circ}$ and $75.8^{\circ}$ ) appeared instead. It should be noted that the diffraction peaks for both $\mathrm{NiO}$ and $\mathrm{CoO}$ were weak from Figure $\mathrm{S} 21$, which was probably caused by the well-dispersed metal species regardless of their location. The pre-reduction treatment could further promote the dispersion as the diffraction peaks for metallic $\mathrm{Ni}$ and Co were also weak from Figure S2r.
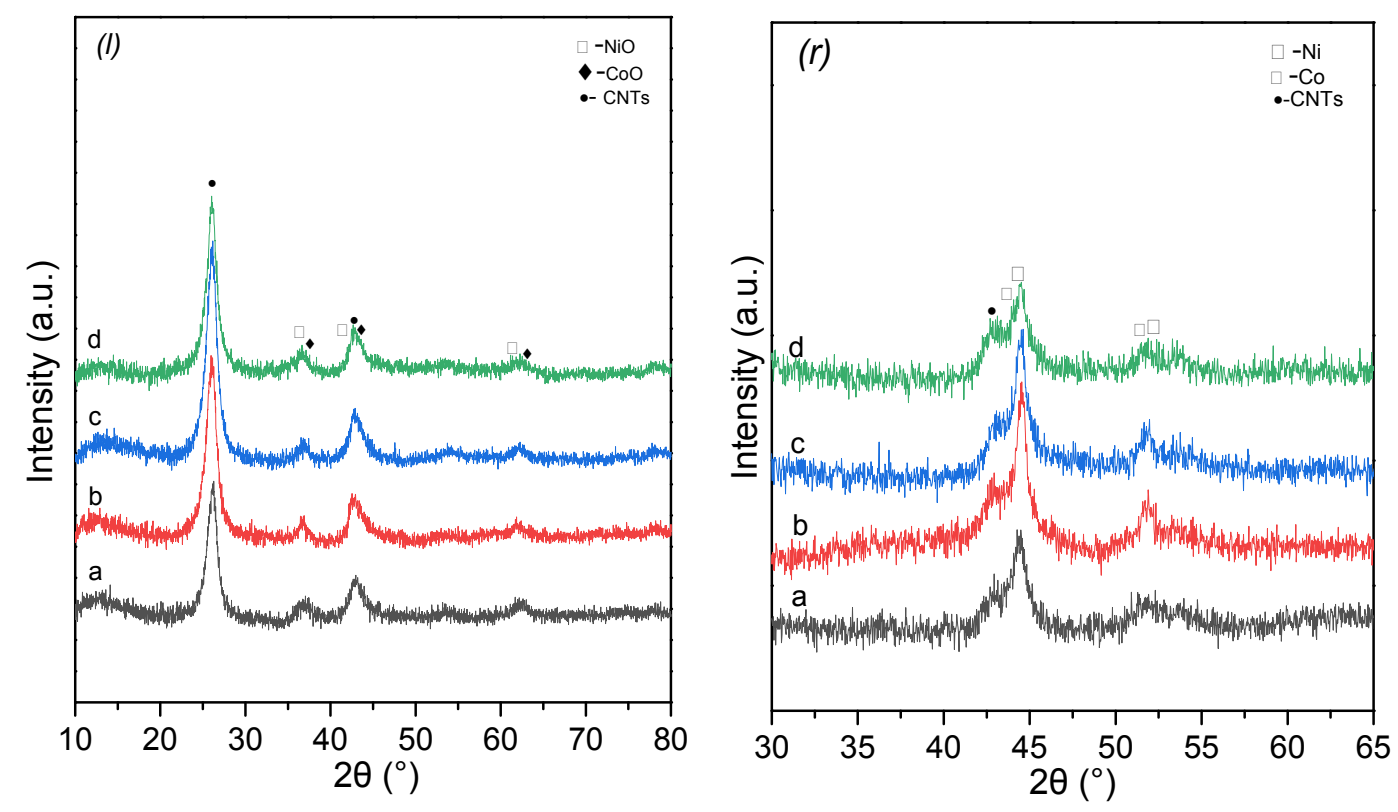

Figure S2 XRD patterns for (l) calcined and (r) reduced catalysts [a: Ni(i)Co(i)/CNTs, b: $\mathrm{Ni}(\mathrm{o}) \mathrm{Co}(\mathrm{o}) / \mathrm{CNTs}, \mathrm{c}: \mathrm{Ni}(\mathrm{i}) \mathrm{Co}(\mathrm{o}) / \mathrm{CNTs}$ and d: $\mathrm{Ni}(\mathrm{o}) \mathrm{Co}(\mathrm{i}) / \mathrm{CNTs}]$ 


\section{Surface analysis by XPS}

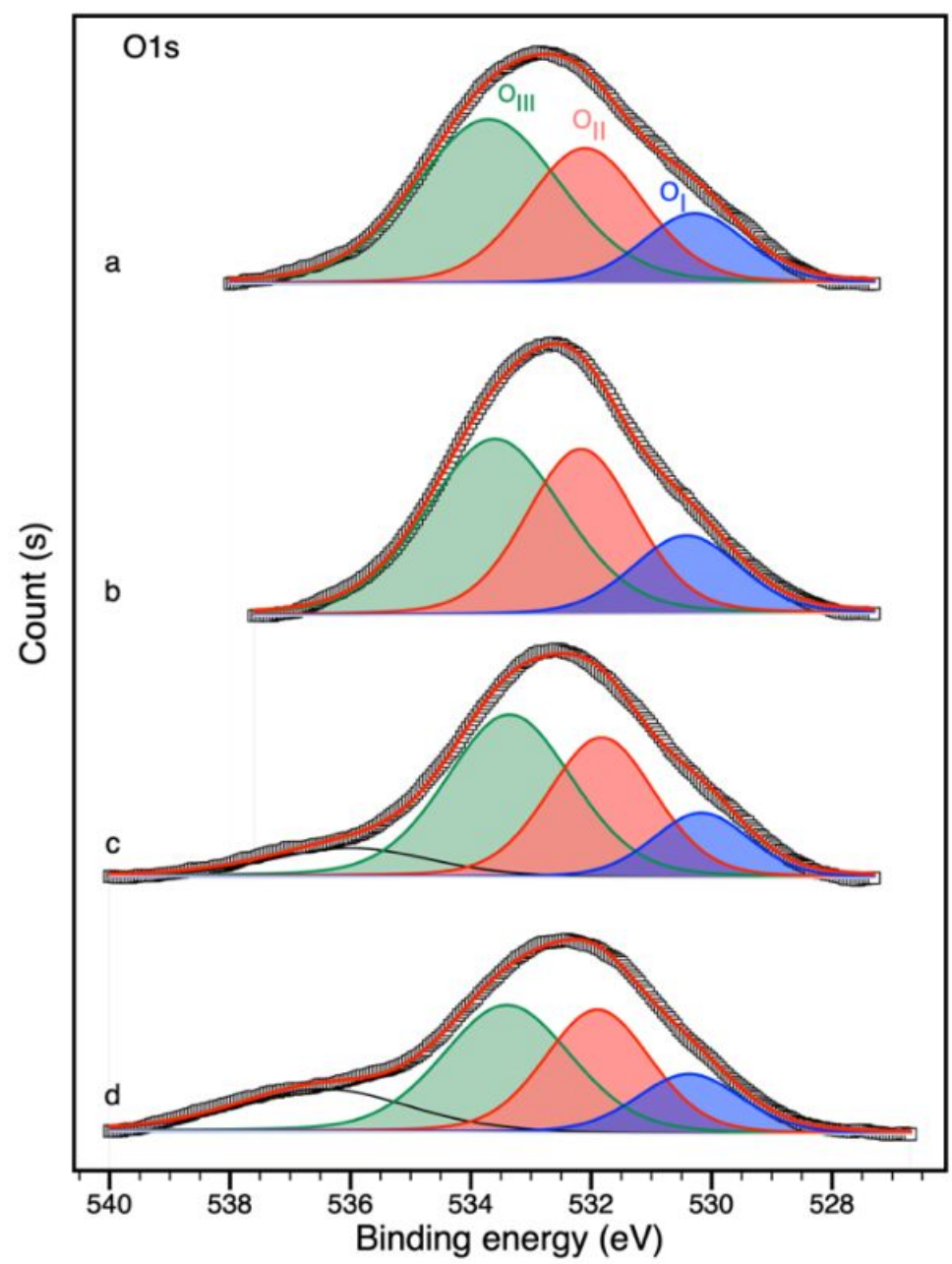

Figure $\mathrm{S} 3 \mathrm{O}$ 1s spectra for the catalyst before reaction [a: Ni(i)Co(i)/CNTs, b: $\mathrm{Ni}(\mathrm{o}) \mathrm{Co}(\mathrm{o}) / \mathrm{CNTs}$, c: $\mathrm{Ni}(\mathrm{i}) \mathrm{Co}(\mathrm{o}) / \mathrm{CNTs}$ and d: Ni(o)Co(i)/CNTs] 


\section{XRD for the spent catalysts}

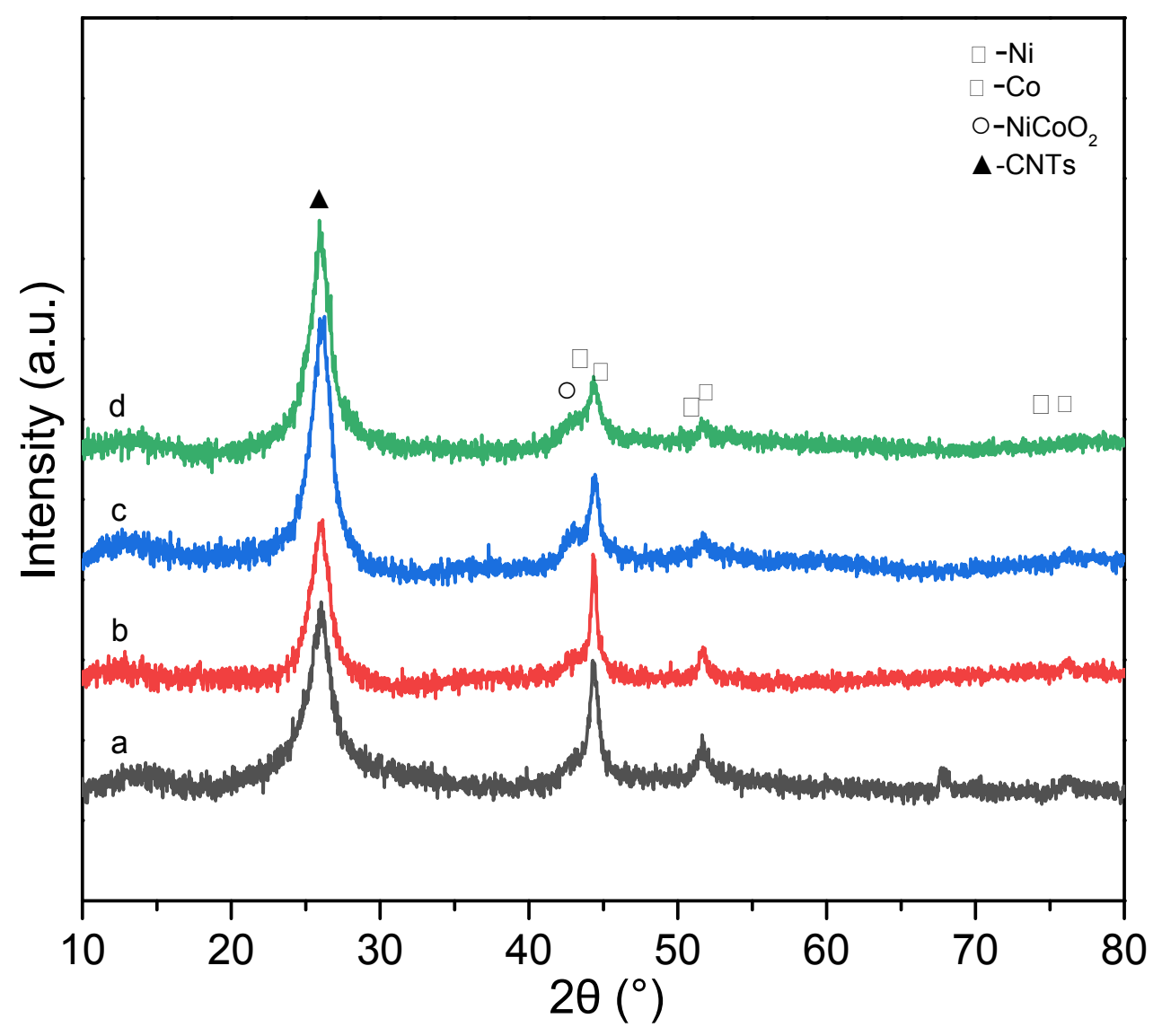

Figure S4 XRD patterns for spent catalysts [a: Ni(i)Co(i)/CNTs, b: Ni(o)Co(o)/CNTs, c: $\mathrm{Ni}(\mathrm{i}) \mathrm{Co}(\mathrm{o}) / \mathrm{CNTs}$ and d: $\mathrm{Ni}(\mathrm{o}) \mathrm{Co}(\mathrm{i}) / \mathrm{CNTs}$ ] 


\section{TG analysis for quantifying coke}

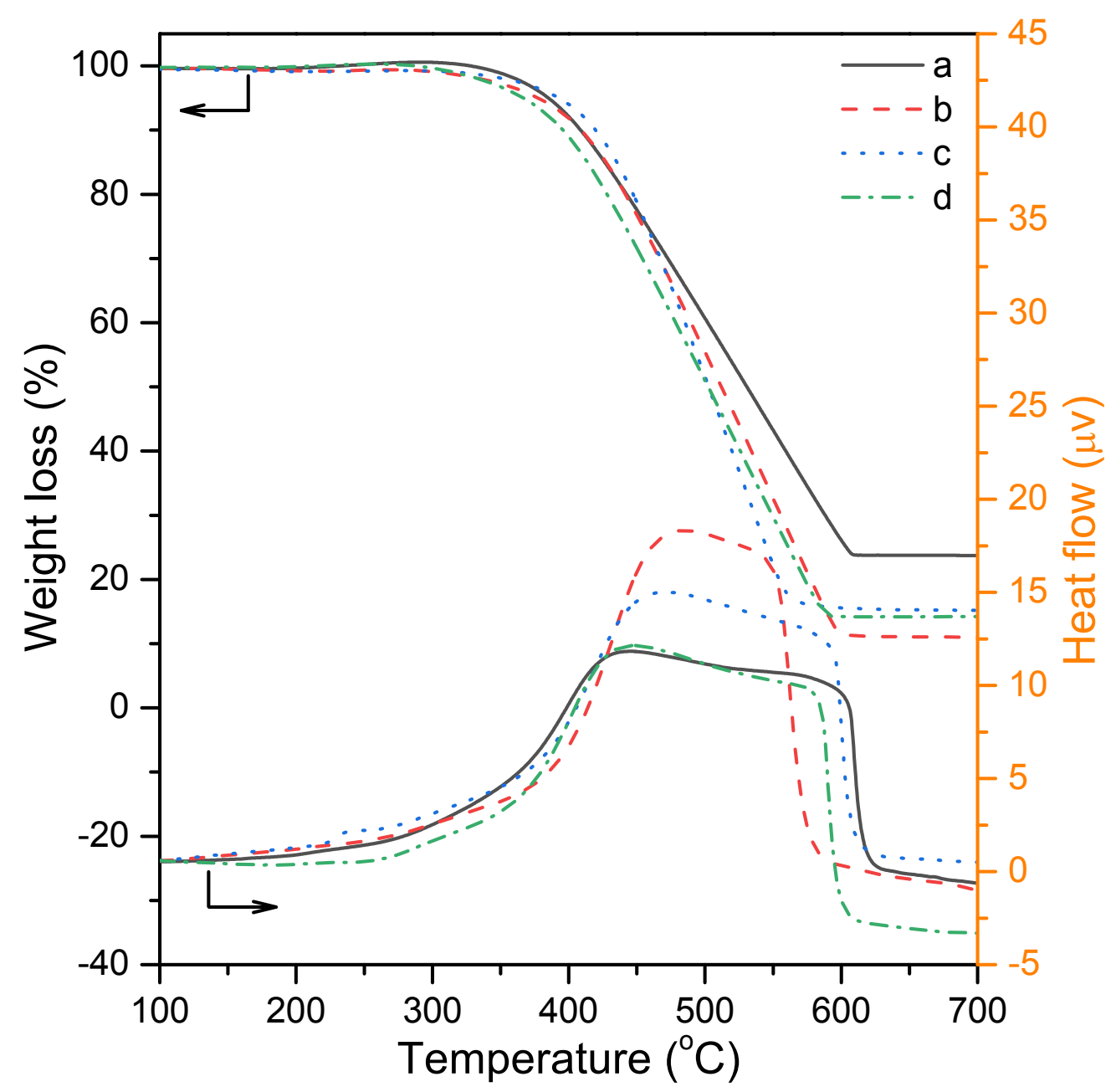

Figure S5 Thermogravimetric analysis for spent catalysts [a: Ni(i)Co(i)/CNTs, b: Ni(o)Co(o)/CNTs, c: $\mathrm{Ni}(\mathrm{i}) \mathrm{Co}(\mathrm{o}) / \mathrm{CNTs}$ and d: Ni(o)Co(i)/CNTs] 


\section{Effect of space velocity on catalytic performances}

The sample Ni(o)Co(i)/CNTs was used to study the effect of space velocity on catalytic performances, the results were gathered in Table S1. The overall conversion of glycerol decreased from $92.2 \%$ to $86.1 \%$ when space velocity increased from 40.8 to $102.0 \mathrm{~h}^{-1}$. Correspondingly, the conversion to gas declined largely from $92.6 \%$ to $75.8 \%$, implying that the generation of gaseous products was restrained under high space velocity conditions. Concerning the composition of gaseous products, hydrogen and $\mathrm{CO}_{2}$ selectivity decreased with the increasing of space velocity. CO selectivity exhibited the opposite trend. High space velocity meant less retention time in catalyst bed, and drove the desorption of reactant and intermediates from catalyst surface, resulting in the loss of glycerol conversion. Similarly, the desorption of $\mathrm{CO}$ was enhanced under the high space velocity conditions, the subsequent water gas shift reaction was weakened, which played the negative effect on hydrogen production.

Table S1 Effect of space velocity on catalytic performances

\begin{tabular}{lllllll}
\hline \multirow{2}{*}{ Space velocity, $\mathrm{h}^{-1}$} & Glycerol & Conversion & \multicolumn{2}{l}{ Selectivity, \% } \\
\cline { 5 - 7 } & Conversion, \% & to gas, \% & $\mathrm{H}_{2}$ & $\mathrm{CO}$ & $\mathrm{CO}_{2}$ & $\mathrm{CH}_{4}$ \\
\hline 40.8 & 92.2 & 92.6 & 80.6 & 9.0 & 72.9 & 3.4 \\
61.2 & 90.4 & 81.5 & 70.1 & 12.7 & 60.0 & 3.2 \\
81.6 & 87.6 & 80.0 & 63.9 & 15.7 & 53.2 & 3.5 \\
102.0 & 86.1 & 75.8 & 57.6 & 19.1 & 44.0 & 3.6 \\
\hline
\end{tabular}

Reaction conditions: $\mathrm{m}_{\text {cat. }}=150 \mathrm{mg}$, atmospheric pressure, reduction temperature $=500^{\circ} \mathrm{C}$, reaction temperature $=400^{\circ} \mathrm{C}$, flowrate of carrier gas $=60 \mathrm{~mL} / \mathrm{min}$, time on stream $=8 \mathrm{~h}$, feedstock $10 \mathrm{wt} . \%$ glycerol in water. 